\title{
Tissue factor expression predicts outcome in children with neuroblastoma: A retrospective study
}

\author{
LAILA M. SHERIEF ${ }^{1}$, TAMER H. HASSAN ${ }^{1}$, MARWA ZAKARIA ${ }^{1}$, MANAR FATHY $^{1}$, \\ ELIA A. ESHAK ${ }^{2}$, MARWA A. BEBARS ${ }^{1}$ and ASMAAESH ${ }^{3}$ \\ ${ }^{1}$ Pediatric Oncology Unit, Zagazig University, Zagazig 44519; ${ }^{2}$ Department of Pathology, Cairo University, Cairo 11956 ; \\ ${ }^{3}$ Department of Clinical Pathology, Zagazig University, Zagazig 44519, Arab Republic of Egypt
}

Received August 15, 2018; Accepted May 24, 2019

DOI: $10.3892 / \mathrm{ol} .2019 .11021$

\begin{abstract}
Previous studies have revealed that the processes of tumor angiogenesis, metastasis and invasiveness are highly dependent on components of the blood coagulation cascade. Tissue factor (TF) is one of the key proteins in coagulation. Cumulative evidence suggested that in addition to its role in coagulation, $\mathrm{TF}$ regulates intracellular signaling pathways that serve an important role in angiogenesis, tumor development and metastasis. In the present study, TF expression in neuroblastoma as well as its association with tumor stage, pathology and outcome were assessed. A total of 40 formalin-fixed paraffin-embedded tissues were evaluated for TF expression by immunohistochemical analysis. Results revealed that TF expression was positive in $75 \%$ of the analyzed tumor tissues. No significant association between TF expression and sex, age, tumor stage or disease pathology was observed. MYCN proto-oncogene bHLH transcription factor (MYCN) was upregulated in $45 \%(n=18)$ of the study cases. Positive TF expression was observed in $94.4 \%$ of patients $(n=17)$ with upregulated $M Y C N$, while $59 \%$ of patients $(n=13)$ with normal MYCN showed positive TF expression $(\mathrm{P}<0.05)$. TF expression was a significant outcome predictor for patients; $18 / 30$ patients (60\%) with positive TF expression succumbed to the disease during the study period. In conclusion, TF may be a promising prognosis indicator for neuroblastoma. Future studies to determine how TF affects the progression and outcome of neuroblastoma, as well as to investigate its potential role as a therapeutic target, are required.
\end{abstract}

\section{Introduction}

Neuroblastoma is the most common extracranial tumor in infants and accounts for $8-10 \%$ of all childhood tumors.

Correspondence to: Professor Tamer H. Hassan, Pediatric Oncology Unit, Zagazig University, 1 Zagazig University Street, Zagazig 44519, Arab Republic of Egypt

E-mail: dr.tamerhassan@yahoo.com

Keywords: tissue factor, neuroblastoma, expression, outcome
Neuroblastoma resulted in $\sim 15 \%$ of pediatric cancer-associated mortalities in 2010. The majority of cases with neuroblastoma (90\%) are diagnosed before the age of 5 years and $30 \%$ of these cases are present within the first year. The median age of diagnosis is 22 months (1). Neuroblastoma is an embryonal tumor derived from precursor cells of the sympathetic nervous system. It is extremely heterogeneous with clinical presentations ranging from spontaneous remission to rapid tumor progression and mortality (2). Neuroblastoma prognosis varies greatly. Children with neuroblastoma exhibit marked variability in outcome when the disease is categorized by age, stage and biological characteristics (3). Patients with low- and intermediate-risk neuroblastoma, characterized by favorable stages and age at time of diagnosis $<1$ year, have a 5-year overall survival $>90 \%$ following chemotherapy and surgical resection. By contrast, the 5-year overall survival for high-risk neuroblastoma, characterized by features such as metastasis, age at diagnosis $>1$ year and upregulated $M Y C N$, is $40-50 \%$ despite intensive treatment protocols that include chemotherapy, surgery, radiation and stem cell transplantation $(4,5)$. The biological behavior of neuroblastoma is influenced by specific factors which are also outcome predictors. These include patient-associated factors, including age at the time of diagnosis and tumor-associated factors, including histology, tumor stage, molecular and cytogenetic features (6). Tissue factor (TF) is the primary cellular initiator of blood coagulation and is a modulator of cancer angiogenesis (7). Hypercoagulability in cancer patients is closely associated with tumor progression (8). Cancer is associated with a 4-fold increase in thrombosis risk, with chemotherapy further increasing the risk (9). A number of risk factors. including leukocyte and platelet counts and circulating levels of tissue factor (TF), P-selectin and D-dimer are also implicated (10).

Cancer cells and their vascular stroma often exhibit procoagulant properties. An example of this is the deregulation of TF expression, as $\mathrm{TF}$ is an important coagulation factor in the extrinsic coagulation pathway (11). Previous studies revealed TF to be a contributing factor in intracellular signaling events through the TF cytoplasmic domain. TF activates protease-activated receptors (PAR) 1 and 2 via the TF/factor VIIa/factor Xa signalling pathway (12). Previous studies revealed a link between tumor cell-associated procoagulant function and cancer biology, as well as TF expression 
and poor patient outcome in hepatocellular, ovarian and gastric carcinoma (13-15). The present study investigated the association of TF expression with tumor pathology, stage and outcome in patients with neuroblastoma.

\section{Materials and methods}

Patients. A total of 40 patients with neuroblastoma treated at the Pediatric Oncology Unit of Zagazig University Hospital (Zagazig, Egypt) between January 2008 and December 2015 were enrolled in the current study. The mean follow-up period was 29.1 months. The mean age of patients was, $2.29 \pm 1.67$ years (age range, 5 months to 5.5 years). There were 24 (60\%) males and $16(40 \%)$ females. All patients were treated according to the Children Oncology Group risk-based protocol (16). Relevant laboratory data, including complete blood count, liver and kidney function tests, serum electrolytes, lactate dehydrogenase, and vanillyl mandelic and homovanillic acid levels, were collected from patient medical records.

Clinical data. Data collected included patient age at diagnosis, sex, clinical symptoms and associated conditions at diagnosis. Data from computed tomography of the chest and abdomen, magnetic resonance imaging of the spine and bone and metaiodobenzylguanidine ${ }^{131} 1$-MIBG) scans were used in the present study. Tumor data collected included tumor site, metastasis, stage according to the International Neuroblastoma Risk Group Staging System (INRGSS) (17), histopathology according to the International Neuroblastoma Pathology Classification (18) and $M Y C N$ expression status according to the recommendation of the European Neuroblastoma Quality Assurance Group (19).

Immunohistochemistry protocol. All samples were untreated biopsy specimens from primary tumors and were examined independently by two pathologists who were blinded to the collected data. Tissue samples were fixed in formalin and embedded in paraffin blocks according to standard procedures (20). Glass slides were cleaned with $95 \%$ ethanol, treated with subbing solution $(0.5 \%$ gelatin in warm deionized water) and air-dried. Alternatively, pretreated slides were used. The tissue samples were cut into 4-6- $\mu \mathrm{m}$ thick sections and mounted onto slides. The sections were subsequently deparaffinized in xylene and rehydrated in a descending alcohol series: The sections were washed in 100\% ethanol twice for $10 \mathrm{~min}$ each time, followed by two 10 min washes in $95 \%$ ethanol and one $1 \mathrm{~min}$ wash in deionized water with stirring. The heating temperature of the antigen retrieval step was $95-100^{\circ} \mathrm{C}$. The sections were incubated with $0.1 \%$ hydrogen peroxidase in deionized water for 5-10 min at room temperature and rinsed in distilled water. Blocking with 2-5\% normal serum (Santa Cruz Biotechnology, Inc.) for $30 \mathrm{~min}$ at room temperature was performed to reduce background staining. Endogenous peroxidase activity was blocked using $0.5-3 \%$ hydrogen peroxide. Expression of TF was determined by incubating with an anti-TF mouse monoclonal antibody (cat no. sc-80952; $100 \mathrm{mg} / \mathrm{ml}$; Santa Cruz Biotechnology, Inc.) for $1 \mathrm{~h}$ at room temperature. Primary antibody incubation was followed by incubation with a horseradish peroxidase-conjugated anti-mouse $\mathrm{IgG}$ secondary antibody (1:100; cat. no. HAF007; R\&D systems, Inc.) for
$1 \mathrm{~h}$ at room temperature. Sections were counterstained using hematoxylin for $30 \mathrm{sec}$ at room temperature. Sections incubated with 2-5\% normal mouse serum (Santa Cruz Biotechnology, Inc.) instead of the primary antibody were used as a control. Neoplastic cells were considered positive when they revealed cytoplasmic or membrane staining.

Immunohistochemistry interpretation. TF expression was visualized with an Axioskop 40 optical microscope (Carl Zeiss AG) at a magnification of $x 100$, and analyzed using Image-Pro Plus image analysis software (version 7; Media Cybernetics, Inc.). Each slide was examined by two pathologists independently, and quantitative analysis of immunohistochemical expression of TF was performed using the method outlined by Sierko et al (20). This method pertains to cancer cell percentage with positive staining and staining intensity. Values from $0-4$ were assigned to cancer cell percentage with positive staining. These values, referred to as the A value, were as follows: 0 , no staining; $1, \leq 10 ; 2,11-50 ; 3,51-75$ and $4,>75 \%$. Staining intensity values, referred to as the B value were assigned from 0-3 and were as follows: 0 , no staining; 1 , weak; 2 , medium and 3 , strong. The immunoreactive score (IRS) was calculated by multiplying the A and B values. The IRS value corresponded with TF expression and was assigned the following values: 1 , negative; 2 , weak; 3 , medium and 4 , strong. The IRS was assessed for cancer cells and tumor vascular endothelial cells that expressed TF as detected by optical microscopy (at least 20 high power fields/sample; magnification, $\mathrm{x} 100$ ).

Statistical analysis. SPSS software (version 15.0; SPSS, Inc.) was used for data handling and statistical analyses. Data are presented as the mean \pm standard deviation for quantitative variables. Categorical variables are expressed as number (\%). Variables were compared using Chi-squared test, Student's t-test, one-way ANOVA and Kruskal-Wallis tests, respectively. Fisher's least significant difference test was used as a post hoc test. The Kaplan-Meier method, log-rank, Breslow and Tarone-Ware tests were for survival curve analysis. The cumulative survival probability $\left(\mathrm{S}_{t}\right)$ is the proportion of patients surviving (or remaining event-free) past interval $t$ and it is computed as follows. Firstly, the proportion of participants surviving past time 0 (the starting time) is defined as $S_{0}=1$ (all participants alive or event-free at time zero or the study start). The proportion surviving past each subsequent interval is computed using principles of conditional probability. The probability that a participant survives past interval 1 is $S_{1}=p_{1}$. The probability that a participant survives past interval 2 means that they had to survive past interval 1 and through interval 2: $S_{2}=P$ (survive past interval 2 ) $=P$ (survive through interval 2) x $\mathrm{P}$ (survive past interval 1), or $\mathrm{S}_{2}=\mathrm{p}_{2} \times \mathrm{S}_{1}$. In general, $\mathrm{S}_{\mathrm{t}+1}=\mathrm{p}_{\mathrm{t}+1} \times \mathrm{S}_{\mathrm{t}}$. Death was used as the event of interest and the status at serial time (points of assessment during follow-up) was either $1=$ event of interest (death) or $0=$ censored. $\mathrm{P}<0.05$ was considered to indicate a statistically significant difference.

\section{Results}

Clinical data. Of the 40 patients, $22(55 \%)$ were $>18$ months old, and 18 (45\%) were $\leq 18$ months old (mean, $2.29 \pm 1.67$ years; range, 5 months to 5.5 years). A total of 24 patients $(60 \%)$ 
Table I. Clinical and pathological characteristics of the patients.

\begin{tabular}{|c|c|}
\hline Variable & Number of patients $(\%$ \\
\hline \multicolumn{2}{|l|}{ Age } \\
\hline Mean & $2.29 \pm 1.67$ years \\
\hline Range & 5 months -5.5 years \\
\hline$\leq 18$ months & $18(45)$ \\
\hline$>18$ months & $22(55)$ \\
\hline \multicolumn{2}{|l|}{ Gender } \\
\hline Males & $24(60)$ \\
\hline Females & $16(40)$ \\
\hline \multicolumn{2}{|l|}{ Primary tumor site } \\
\hline Abdomen & $34(85)$ \\
\hline Mediastinum & $4(10)$ \\
\hline Neck & $2(5)$ \\
\hline \multicolumn{2}{|l|}{ Metastatic sites } \\
\hline Bone marrow & $22(55)$ \\
\hline Bone & $20(50)$ \\
\hline Eye & $14(35)$ \\
\hline Liver & $4(10)$ \\
\hline \multicolumn{2}{|l|}{ Stages } \\
\hline Stage I & $0(0)$ \\
\hline Stage II & $4(10)$ \\
\hline Stage III & $12(30)$ \\
\hline Stage IV & $24(60)$ \\
\hline \multicolumn{2}{|l|}{ Pathology } \\
\hline Favorable Shimada & $20(50)$ \\
\hline Unfavorable Shimada & $20(50)$ \\
\hline \multicolumn{2}{|c|}{$\begin{array}{l}\text { MYCN proto-oncogene bHLH } \\
\text { transcription factor status }\end{array}$} \\
\hline Amplified & $18(45)$ \\
\hline Non-amplified & $22(55)$ \\
\hline \multicolumn{2}{|l|}{ Risk stratification } \\
\hline Low & $4(10)$ \\
\hline Intermediate & $6(15)$ \\
\hline High & $30(75)$ \\
\hline \multicolumn{2}{|l|}{ Tissue factor expression } \\
\hline Positive (High) & $6(15)$ \\
\hline Positive (Moderate) & $10(25)$ \\
\hline Positive (Weak) & $14(35)$ \\
\hline Negative & $10(25)$ \\
\hline
\end{tabular}

were male while 16 patients $(40 \%)$ were female (Table I). The primary tumor sites included the abdomen (34/40; 85\%), mediastinum $(4 / 40 ; 10 \%)$ and neck $(2 / 40 ; 5 \%)$. The bone marrow was the most common site of metastasis $(22 / 40 ; 55 \%)$ followed by bone $(20 / 40 ; 50 \%)$ and the eye $(14 / 40 ; 35 \%)$ patients. Patients had $>1$ metastatic site. A total of 24 patients $(60 \%)$ were diagnosed at stage IV, 12 patients (30\%) at stage III and 4 patients $(10 \%)$ at stage II. Histology was favorable for 20 out of 40 patients (50\%). MYCN amplification was reported in $18(45 \%)$ patients, while no amplification was observed in 22 $(55 \%)$ cases. Risk stratification revealed that $30(75 \%)$ cases
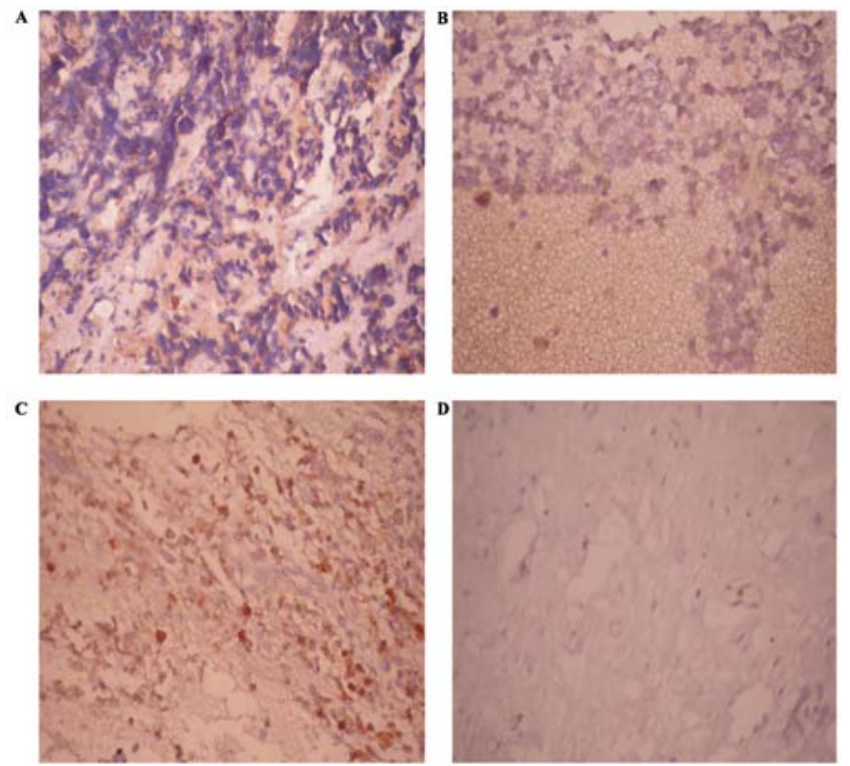

Figure 1. Representative images from 4 tumors, at a magnification of x100, showing immunohistochemical staining with anti-TF antibody. (A) Positive TF expression with strong immunoreactivity. (B) Positive TF expression with moderate immunoreactivity. (C) Positive TF expression with weak immunoreactivity. (D) Negative TF expression with no immunoreactivity. Non-linear adjustments were not applied to the images. TF, tissue factor.

were classified as high risk, $6(15 \%)$ were intermediate risk and $4(10 \%)$ were classified as low risk.

Immunohistochemical analysis. Varying levels of TF expression were observed in 30 out of 40 cases (75\%), namely, weak intensity in $14(35 \%)$, moderate intensity in $10(25 \%)$ and high intensity in $6(15 \%)$, while $10(25 \%)$ cases showed no TF expression (Table I; Fig. 1). In the present study, $60 \%$ of unfavorable 'Shimada pathology' was detected in patients with positive TF expression, while only $20 \%$ was detected in patients with negative TF expression. This difference was statistically insignificant ( $\mathrm{P}>0.05$; Table II).

There was a significant association between TF expression and patient outcome. All patients with negative TF expression survived, whereas $18(60 \%)$ patients with positive TF expression succumbed, $6(20 \%)$ patients survived while another $6(20 \%)$ were still undergoing treatment during the study period $(\mathrm{P}<0.05$; Table II). The mean follow-up period was 29.1 months. The mean survival time for patients with negative TF expression was 59.8 months as opposed to 18.87 months for those with positive TF expression ( $\mathrm{P}<0.05$; Table III). All patients with negative tissue factor expression survived and completed their treatment successfully. The mean survival time is based on the last follow up point of the study and ranged from 28-95 months. Survival distributions for varying levels of TF expression were tested, and results revealed a significant difference between patients with and without TF expression $(\mathrm{P}<0.05$; Table IV). There were no mortalities reported in patients with negative TF expression (Table IV; Fig. 2). In the present study, no association was observed between TF intensity staining and variables including sex, age, clinical symptoms, tumor stage, risk stratification, pathology, MYCN amplification and outcome (P>0.05; Table SI). 
Table II. Association between tissue factor expression and tumor stage, pathology, risk stratification and patient outcome.

\begin{tabular}{|c|c|c|c|}
\hline \multirow[b]{2}{*}{ Variable } & \multicolumn{2}{|c|}{ Tissue factor expression } & \multirow[b]{2}{*}{ P-value } \\
\hline & Negative $(\mathrm{n}=10)(\%)$ & Positive $(n=30)(\%)$ & \\
\hline \multicolumn{4}{|l|}{ Stage } \\
\hline II & $0(0.0)$ & $4(13.3)$ & 0.64 \\
\hline III & $4(40)$ & $8(26.7)$ & \\
\hline IV & $6(60)$ & $18(60)$ & \\
\hline \multicolumn{4}{|l|}{ Risk stratification } \\
\hline Low & $0(0.0)$ & $4(13.3)$ & 0.16 \\
\hline Intermediate & $4(40)$ & $2(6.7)$ & \\
\hline High & $6(60)$ & $24(80)$ & \\
\hline \multicolumn{4}{|l|}{ Pathology } \\
\hline Unfavorable & $2(20)$ & $18(60)$ & 0.3 \\
\hline Favorable & $8(80)$ & $12(40)$ & \\
\hline \multicolumn{4}{|l|}{ Outcome } \\
\hline Mortality & $0(0.0)$ & $18(60)$ & 0.002 \\
\hline Cured & $10(100)$ & $6(20)$ & \\
\hline Under treatment & $0(0.0)$ & $6(20)$ & \\
\hline \multicolumn{4}{|l|}{ Age } \\
\hline$\leq 18$ months & $6(60)$ & $12(40)$ & 0.79 \\
\hline$>18$ months & $4(40)$ & $18(60)$ & \\
\hline \multicolumn{4}{|l|}{ Gender } \\
\hline Male & $8(80)$ & $16(53.3)$ & 0.59 \\
\hline Female & $2(20)$ & $14(46.7)$ & \\
\hline \multicolumn{4}{|c|}{ MYCN proto-oncogene bHLH transcription factor status } \\
\hline Amplified & $1(10)$ & $17(56.7)$ & 0.01 \\
\hline Non-amplified & $9(90)$ & $13(43.3)$ & \\
\hline
\end{tabular}

Chi-square test was used for these comparisons.

Similarly, no significant link was identified between patient outcome and sex, age, clinical symptoms, tumor stage, risk stratification, pathology and MYCN amplification ( $\mathrm{P}>0.05)$. Patients who succumbed to the disease were found to have a higher percentage of $M Y C N$ amplification, however, this did not reach a statistically significant level $(\mathrm{P}=0.08)$. The present study revealed a significant association between TF expression and MYCN amplification. Only $10 \%$ of cases with negative TF expression showed MYCN amplification, as opposed to $56.7 \%$ of cases with positive $\mathrm{TF}$ expression ( $\mathrm{P}=0.01$; Table II).

\section{Discussion}

TF is an evolutionary conserved glycoprotein that serves an important role in the pathogenesis of cancer. TF affects a variety of pathological processes, including tumor-associated angiogenesis, thrombogenicity, tumor growth and metastasis (21). Additionally, high levels of TF expression were associated with increased expression of vascular endothelial growth factor and vascularity as development of blood vessels in tumors is required for tumor growth and spread (22).

Previous studies revealed that TF expression was higher in patients with KRAS proto-oncogene GTPase and tumor protein 53 mutations, suggesting that TF expression is a poor prognostic factor $(23,24)$. TF upregulation parallels the expression of several mutant oncogenes including epidermal growth factor receptor, erb-b2 receptor tyrosine kinase 2 and promyelocytic leukemia-retinoic acid receptor $\alpha$. Previous studies have revealed that the upregulation of TF is associated with the upregulation of the aforementioned oncogenes in colorectal cancer cells, mammary glands, cutaneous tissue, astrocytes and blood $(23,24)$. Although upregulation of TF is often detected on the surface of tumor endothelial cells, determining its effect on prognosis and patient survival remains challenging (25). To the best of our knowledge, the present study is the first relating immunohistochemical analysis of TF expression in children with neuroblastoma and its role in tumor pathology, stage and patient outcome. The current study revealed increased TF expression in 30/40 (75\%) patients. Similarly, Maciel et al (26), reported increased TF expression in 38/41 (88.3\%) cases of nephroblastoma. In a previous study by Abdulkadir et al (27), $73 \%$ of patients diagnosed with prostate cancer had positive $\mathrm{TF}$ expression, which was positively correlated with preoperative serum prostate specific antigen levels. As demonstrated by Callander et al (28), TF upregulation is a characteristic marker of certain neoplasms. At least $60 \%$ of epithelial neoplasms, 
Table III. Mean survival time for patients with and without tissue factor expression.

\begin{tabular}{|c|c|c|c|c|c|c|c|c|}
\hline Tissue factor expression & $\mathrm{n}$ & $\begin{array}{c}\text { Mean } \\
\text { (months) }\end{array}$ & $\begin{array}{l}\text { Standard } \\
\text { deviation } \\
\text { (months) }\end{array}$ & $\begin{array}{l}\text { Median } \\
\text { (months) }\end{array}$ & $\begin{array}{c}\text { Minimum } \\
\text { (months) }\end{array}$ & $\begin{array}{c}\text { Maximum } \\
\text { (months) }\end{array}$ & t-test & P-value \\
\hline Negative tissue factor expression & 10 & 59.80 & 24.087 & 61.00 & 28 & 95 & 4.64 & $<0.001$ \\
\hline Positive tissue factor expression & 30 & 18.87 & 24.176 & 9.00 & 1 & 90 & & \\
\hline Total & 40 & 29.10 & 29.845 & 13.00 & 1 & 95 & & \\
\hline
\end{tabular}

Table IV. Tests of equality of survival distributions for the upregulated and normal expression levels of tissue factor.

\begin{tabular}{lccr}
\hline Test & Chi-square test & Degrees of freedom & P-value \\
\hline Log rank (mantel-cox) & 10.048 & 1 & 0.002 \\
Breslow (generalized wilcoxon) & 8.860 & 1 & 0.003 \\
Tarone-ware & 9.523 & 1 & 0.002
\end{tabular}

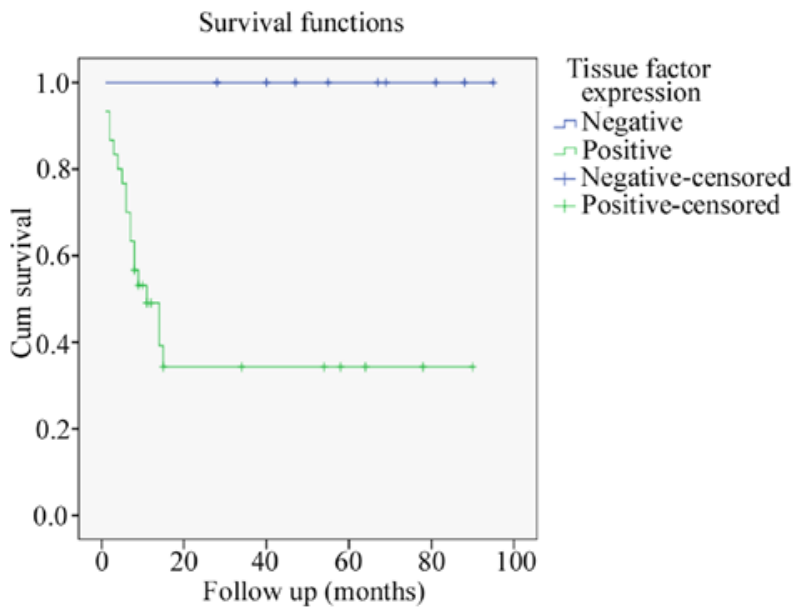

Figure 2. Kaplan-Meier survival curves in patients with and without TF expression. There is a significant difference between patients with and without TF expression as regarding survival $(\mathrm{P}=0.002)$. No mortality was reported in patients with negative TF expression.

and up to $100 \%$ of gastrointestinal carcinomas, express high levels of TF. TF expression has been detected in breast cancer, lung carcinomas, colon cancer and gliomas (29-32). In the aforementioned malignancies, TF is expressed by the tumor cells or adjacent stromal cells. This has been correlated with tumor grading, metastasis and poor prognosis. TF upregulation has been associated with tumorigenesis with high procoagulant activity observed in tumor cells (29-32).

TF is involved in hematogenous metastasis where TF levels in metastatic cells may be 1,000-fold higher than in non-metastatic cells in leukemia and melanoma $(33,34)$. TF enhances metastasis by inducing a fibrin coating on malignant cells, trapping the cells in the microvasculature, thereby aiding metastasis. Additionally, thrombin activates platelets, leading to the formation of platelet-fibrin thrombi in the microvasculature (35). Clot formation around the tumor cells in circulation prevents the removal of tumor cells by natural-killer cells (35). TF expression by the tumor and host cells initiates direct or indirect signaling events that support tumor development by distinct mechanisms. TF supports cell migration and cellular trafficking by binding to the protein filamin-A, resulting in reorganization of actin filaments and cell migration (36). Regulation of cell motility by binding to its ligand factor VIIa is another pathway by which TF may directly influence tumor metastasis (37). The present study revealed TF expression in 18/24 (75\%) patients with stage IV neuroblastoma, and 8/12 (67\%) patients with stage III neuroblastoma. However, results revealed no significant statistical association between TF expression and neuroblastoma stages. The present study was based on a small patient number with a high stage IV percentile (60\%).

Previous studies have revealed an association between TF expression and metastases in various types of cancer including prostate cancer, human glioma, colorectal cancer, breast cancer, hepatocellular carcinoma and pancreatic duct carcinoma (27,32,38-41). Additionally, it has been shown that TF serves a role in tumor-associated angiogenesis and its expression levels are associated with the metastatic potential of numerous hematological malignancies (42). In the present study, a significant association between TF expression and age and sex of the patients was not observed. These results are similar to previous studies in human non-small cell lung carcinoma, colorectal carcinoma, hepatocellular carcinoma and pancreatic ductal adenocarcinoma (43-46). As pathological symptoms of neuroblastoma have been used to further analyze these tumors, Shimada et al (18), initially classified these tumors as favorable and unfavorable by combining age with the extent of tumor differentiation, presence of schwannian stroma components and cellular information from the mitosis-karyorrhexis index. In the present study, $60 \%$ of unfavorable 'Shimada pathology' was detected in patients with positive TF expression, while only $20 \%$ was detected in patients with negative $\mathrm{TF}$ expression. This difference was statistically insignificant $(\mathrm{P}>0.05)$.

Previous studies have shown no significant association between TF expression and favorable or unfavorable 
nephroblastoma histology (26). Similarly, no association between pathological grade and TF expression in prostatic cancer has been found (47). However, a number of studies have revealed an association between the histological grading of a tumor and TF expression. Kakkar et al (48) reported that TF expression was associated with histological grade in pancreatic cancer and a significant linear trend was detected with stronger immunoreactivity observed in poorly differentiated tumors. Similar results have been documented in human glioma and breast cancer $(29,32)$.

The $M Y C N$ gene was the first oncogene revealed to be amplified in solid malignancies and the only consistently amplified gene in neuroblastoma (49). The MYCN gene has been used by The Children's Oncology Group to assign newly diagnosed neuroblastoma patients to a high-risk group requiring intensive multimodal therapy (50). In the present study, all patients were tested for $M Y C N$ amplification. It was amplified in $18 / 40$ (45\%) patients and was not amplified in 22/40 (55\%) patients. There was an association between $M Y C N$ amplification and TF expression, whereby only $10 \%$ of those with negative TF expression had amplified $M Y C N$, while $56.7 \%$ of those with positive TF expression had amplified MYCN. The link between $\mathrm{TF}$ and $M Y C N$ expression may improve the value of $M Y C N$ as a prognostic indicator in children with neuroblastoma.

In the present study, TF expression was significantly associated with patient outcome. All patients with negative TF expression survived, whereas 18/30 (60\%) cases with positive TF expression succumbed to the disease. These results were similar to a previous study where an association between TF expression and prognosis in patients with nephroblastoma and increased immunohistochemical detection of TF expression was the most important risk factor for recurrence and mortality according to bivariate and multivariate analysis (26). Furthermore, immunohistochemical TF expression was an important independent predictor of mortality in a cohort of patients with clear cell renal cell carcinoma (51). Rao et al (23) reported that TF expression was markedly higher in patients with poor differentiation in colorectal carcinoma based on Dukes' staging system, whereas patients with low TF expression had longer disease-free survival and overall survival compared with patients with high TF expression (23). Akashi et al (47) revealed that in patients with metastatic prostate cancer treated with androgen-withdrawal therapy, TF expression was not associated with therapeutic response; however, patients with TF positive tumors had a shorter survival rate compared with patients with TF negative tumors. Hamada et al (32) did not demonstrate a correlation between TF expression and patient outcome in human glioma; however, an association with malignancy grade was observed. In the present study, no significant association was found between TF staining intensity and pathology, stage and age of the patients. Nitori et al (46) reported that patients with pancreatic duct carcinoma with negative TF expression had markedly improved survival time compared with patients with positive TF expression. Furthermore, increased levels of TF expression are an independent risk factor for poor survival in patients with solid tumors such as breast cancer, colorectal carcinoma, hepatocellular carcinoma and pancreatic duct carcinoma $(29,38,44-46)$. However, more extensive and disease-specific clinical analysis is warranted to establish whether tumor-associated TF levels as well as changes in circulating TF, possess independent prognostic and predictive utility (52). In summary, TF is a unique molecule that may be explored further and utilized in various ways in order to treat human cancer.

The present study had a number of limitations. A limited number of patients were enrolled, however, this should be read in light of the rarity of the disease. Additionally, the present study focused on TF and its relationship with outcome and other well-known risk factors. Future larger studies with a wide scope that take into consideration all variables that may impact outcome are required. In conclusion, the results of the present study revealed that TF expression may be useful for the prognosis of patients with neuroblastoma. The mechanisms underlying the effects of TF expression on the progression of neuroblastoma and patient outcome, as well as its potential for the development of novel therapeutic strategies, require further investigation.

\section{Acknowledgements}

Not applicable.

\section{Funding}

No funding was received.

\section{Availability of data and materials}

The datasets used and/or analyzed during the current study are available from the corresponding author on reasonable request.

\section{Authors' contributions}

LMS and THH designed the study. LMS participated in the data analyses, manuscript writing and revision. THH performed the statistical analysis and participated in manuscript writing and revision. MZ, MF and MAB collected the clinicopathological data, performed statistical analysis and participated in manuscript writing. EAE performed the histopathological examinations and analyzed $M Y C N$ upregulation and TF expression. AE performed routine laboratory work for the patients. All authors read and approved the final manuscript.

\section{Ethics approval and consent to participate}

The present study was approved by the Institutional Review Board of the Faculty of Medicine, Zagazig University (Zagazig, Egypt). The study was performed according to the Helsinki Declaration as revised in 2000. Written informed consent was obtained from the legal guardians of the patients.

\section{Patient consent for publication}

Not applicable.

\section{Competing interests}

The authors declare that they have no competing interests. 


\section{References}

1. Maris JM: Recent advances in neuroblastoma. N Engl J Med 362: 2202-2211, 2010.

2. Maris JM, Hogarty MD, Bagarteii $R$ and Cohn SL: Neuroblastoma. Lancet 369: 2106-2120, 2007.

3. Goto S, Umehara S, Gerbing RB, Stram DO, Brodeur GM, Seeger RC, Lukens JN, Matthay KK and Shimada H Histopathology (International Neuroblastoma Pathology Classification) and MYCN status in patients with peripheral neuroblastic tumors: A report from the Children's Cancer Group. Cancer 92: 2699-2708, 2001.

4. Irwin MS and Park JR: Neuroblastoma: Paradigm for precision medicine. Pediatr Clin North Am 62: 225-256, 2015.

5. Park JR, Bagatell R, London WB, Maris JM, Cohn SL, Mattay KK and Hogarty M; COG Neuroblastoma Committee: Children's Oncology Group's 2013 blueprint for research: Neuroblastoma. Pediatr Blood Cancer 60: 985-993, 2013.

6. Brodeur GM: Molecular basis for heterogeneity in human neuroblastomas. Eur J Cancer 31A: 505-510, 1995.

7. Rak J, Milsom C and Yu J: Tissue factor in cancer. Curr Opin Hematol 15: 522-528, 2008.

8. Rickles FR: Mechanisms of cancer-induced thrombosis in cancer. Pathophysiol Haemost Thromb 35: 103-110, 2006

9. Khorana AA, Kuderer NM, Culakova E, Lyman GH and Francis CW: Development and validation of a predictive model for chemotherapy-associated thrombosis. Blood 111: 4902-4907, 2008.

10. Ay C, Dunkler D, Marosi C, Chiriac AL, Vormittag R, Simanek R, Quehenberger P, Zielinski C and Pabinger I: Prediction of venous thromboembolism in cancer patients. Blood 116: 5377-5382, 2010.

11. Mackman N: Triggers, targets and treatments for thrombosis. Nature 451: 914-918, 2008

12. Versteeg $\mathrm{HH}$ and Ruf W: Emerging insights in tissue factor-dependent signaling events. Semin Thromb Hemost 32 : 24-32, 2006

13. Kaido T, Oe $\mathrm{H}$, Yoshikawa A, Mori A, Arii $\mathrm{S}$ and Imamura M: Tissue factor is a useful prognostic factor of recurrence in hepatocellular carcinoma in 5-year survivors. Hepatogastroenterology 52: 1383-1387, 2005.

14. Han LY, Landen CN Jr, Kamat AA, Lopez A, Bender DP, Mueller P, Schmandt R, Gershenson DM and Sood AK: Preoperative serum tissue factor levels are an independent prognostic factor in patients with ovarian carcinoma. J Clin Oncol 24 755-761, 2006.

15. Yamashita $H$, Kitayama J, Ishikawa $M$ and Nagawa $H$ : Tissue factor expression is a clinical indicator of lymphatic metastasis and poor prognosis in gastric cancer with intestinal phenotype. J Surg Oncol 95: 324-331, 2007.

16. Matthay KK, Villablanca JG, Seeger RC, Stram DO, Harris RE, Ramsay NK, Swift P, Shimada H, Black CT, Brodeur GM, et al: Treatment of high-risk neuroblastoma with intensive chemotherapy, radiotherapy, autologous bone marrow transplantation, and 13-cis-retinoic acid. Children's Cancer Group. N Engl J Med 341: 1165-1173, 1999.

17. Castleberry RP, Pritchard J, Ambros P, Berthold F, Brodeur GM, Castel V, Cohn SL, De Bernardi B, Dicks-Mireaux C, Frappaz D, et al: The international neuroblastoma risk groups (INRG): A preliminary report. Eur J Cancer 33: 2113-2116, 1997.

18. Shimada H, Ambros IM, Dehner LP, Hata J, Joshi VV and Roald B: Terminology and morphologic criteria of neuroblastic tumors: Recommendations by the International Neuroblastoma Pathology Committee. Cancer 86: 349-363, 1999.

19. Theissen J, Boensch M, Spitz R, Betts D, Stegmaier S, Christiansen H, Niggli F, Schilling F, Schwab M, Simon T, et al: Heterogeneity of the MYCN oncogene in neuroblastoma. Clin Cancer Res 15: 2085-2090, 2009.

20. Sierko E, Wojtukiewicz MZ,Zimnoch L and Kisiel W: Expression of tissue factor pathway inhibitor (TFPI) in human breast and colon cancer tissue. Thromb Haemost 103: 198-204, 2010.

21. Eisenreich A, Bolbrinker $\mathbf{J}$ and Leppert U: Tissue factor: A conventional or alternative target in cancer therapy. Clin Chem 62: 563-570, 2016.

22. Khorana AA, Ahrendt SA, Ryan CK, Francis CW, Hruban RH, $\mathrm{Hu}$ YC, Hostetter G, Harvey J and Taubman MB: Tissue factor expression, angiogenesis, and thrombosis in pancreatic cancer. Clin Cancer Res 13: 2870-2875, 2007.
23. Rao B, Gao Y, Huang J, Gao X, Fu X, Huang M, Yao J, Wang J, $\mathrm{Li}$ W, Zhang J, et al: Mutations of p53 and K-ras correlate TF expression in human colorectal carcinomas: TF downregulation as a marker of poor prognosis. Int J Colorectal Dis 26: 593-601, 2011.

24. Yu JL, May L, Lhotak V, Shahrzad S, Shirasawa S, Weitz JI, Coomber BL, Mackman N and Rak JW: Oncogenic events regulate tissue factor expression in colorectal cancer cells: Implications for tumor progression and angiogenesis. Blood 105 : 1734-1741, 2005.

25. Staton CA, Chetwood ASA, Cameron IC, Cross SS, Brown NJ and Reed MW: The angiogenic switch occurs at the adenoma stage of the adenoma carcinoma sequence in colorectal cancer. Gut 56: 1426-1432, 2007.

26. Maciel EO, Carvalhal GF, da Silva VD, Batista EL Jr and Garicochea B: Increased tissue factor expression and poor nephroblastoma prognosis. J Urol 182: 1594-1599, 2009.

27. Abdulkadir SA, Carvalhal GF, Kaleem Z, Kisiel W, Humphrey PA, Catalona WJ and Milbrandt J: Tissue factor expression and angiogenesis in human prostate carcinoma. Hum Pathol 31: 443-447, 2000

28. Callander NS, Varki N and Rao LV: Immunohistochemical identification of tissue factor in solid tumors. Cancer 70: 1194-1201, 1992.

29. Ueno T, Toi M, Koike M, Nakamura S and Tominaga T: Tissue factor expression in breast cancer tissues: Its correlation with prognosis and plasma concentration. Br J Cancer 83: 164-170, 2000.

30. Sawada M, Miyake S, Ohdama S, Matsubara O, Masuda S, Yakumaru K and Yoshizawa Y: Expression of tissue factor in non-small-cell lung cancers and its relationship to metastasis. $\mathrm{Br}$ J Cancer 79: 472-477, 1999.

31. Shigemori C, Wada H, Matsumoto K, Shiku H, Nakamura S and Suzuki H: Tissue factor expression and metastatic potential of colorectal cancer. Thromb Haemost 80: 894-898, 1998.

32. Hamada K, Kuratsu J, Saitoh Y, Takeshima H, Nishi T and Ushio Y: Expression of tissue factor correlates with grade of malignancy in human glioma. Cancer 77: 1877-1883, 1996.

33. Rickles FR, Hair GA, Zeff RA, Lee E and Bona RD: Tissue factor expression in human leukocytes and tumor cells. Thromb Haemost 74: 391-395, 1995.

34. Amirkhosravi A, Meyer T, Chang JY, Amaya M, Siddiqui F, Desai $\mathrm{H}$ and Francis JL: Tissue factor pathway inhibitor reduces experimental lung metastasis of B16 melanoma. Thromb Haemost 87: 930-936, 2002.

35. Palumbo JS, Talmage KE, Massari JV, La Jeunesse CM, Flick MJ, Kombrinck KW, Jirousková M and Degen JL: Platelets and fibrin(ogen) increase metastatic potential by impeding natural killer cell-mediated elimination of tumor cells. Blood 105: 178-185, 2005

36. Abe K, Shoji M, Chen J, Bierhaus A, Danave I, Micko C, Casper K, Dillehay DL, Nawroth PP and Rickles FR: Regulation of vascular endothelial growth factor production and angiogenesis by the cytoplasmic tail of tissue factor. Proc Natl Acad Sci USA 96: 8663-8668, 1999.

37. Dorfleutner A, Hintermann E, Tarui T, Takada Y and Ruf W: Cross-talk of integrin alpha3beta1 and tissue factor in cell migration. Mol Biol Cell 15: 4416-4425, 2004.

38. Seto S, Onodera H, Kaido T, Yoshikawa A, Ishigami S, Arii S and Imamura M: Tissue factor expression in human colorectal carcinoma: Correlation with hepatic metastasis and impact on prognosis. Cancer 88: 295-301, 2000.

39. Zhou JN, Ljungdahl S, Shoshan MC, Swedenborg J and Linder S: Activation of tissue-factor gene expression in breast carcinoma cells by stimulation of the RAF-ERK signaling pathway. Mol Carcinog 21: 234-243, 1998.

40. Poon RT, Lau CP, Ho JW, Yu WC, Fan ST and Wong J: Tissue factor expression correlates with tumor angiogenesis and invasiveness in human hepatocellular carcinoma. Clin Cancer Res 9: 5339-5345, 2003

41. Ueda C, Hirohata Y, Kihara Y, Nakamura H, Abe S, Akahane K, Okamoto K, Itoh $\mathrm{H}$ and Otsuki M: Pancreatic cancer complicated by disseminated intravascular coagulation associated with production of tissue factor. J Gastroenterol 36: 848-850, 2001.

42. Versteeg HH, Spek CA, Peppelenbosch MP and Richel DJ: Tissue factor and cancer metastasis: The role of intracellular and extracellular signaling pathways. Mol Med 10: 6-11, 2004.

43. Koomägi R and Volm M: Tissue-factor expression in human non-small-cell lung carcinoma measured by immunohistochemistry: Correlation between tissue factor and angiogenesis. Int $\mathbf{J}$ Cancer 79: 19-22, 1998 
44. Lykke $\mathrm{J}$ and Nielsen $\mathrm{HJ}$ : The role of tissue factor in colorectal cancer. Eur J Surg Oncol 29: 417-422, 2003.

45. Poon RT, Lau CP, Cheung ST, Yu WC and Fan ST: Quantitative correlation of serum levels and tumor expression of vascular endothelial growth factor in patients with hepatocellular carcinoma. Cancer Res 63: 3121-3126, 2003.

46. Nitori N, Ino Y, Nakanishi Y, Yamada T, Honda K, Yanagihara K, Kosuge T, Kanai Y, Kitajima M and Hirohashi S: Prognostic significance of tissue factor in pancreatic ductal adenocarcinoma. Clin Cancer Res 11: 2531-2539, 2005.

47. Akashi T, Furuya Y, Ohta S and Fuse H: Tissue factor expression and prognosis in patients with metastatic prostate cancer. Urology 62: 1078-1082, 2003.

48. Kakkar AK, Lemoine NR, Scully MF, Tebbutt $S$ and Williamson RC: Tissue factor expression correlates with histological grade in human pancreatic cancer. Br J Surg 82: 1101-1104, 1995.

49. Schwab M, Shimada H, Joshi V and Brodeur GM: Neuroblastic tumors of adrenal glandand sympathetic nervous system. In: Pathology and Genetics of Tumors of the Nervous System. Kleihues P and Cavenee WK (eds). World Health Organization, IARC, Lyon, pp153-161, 2000.
50. Maris JM, Weiss MJ, Guo C, Gerbing RB, Stram DO, White PS, Hogarty MD, Sulman EP, Thompson PM, Lukens JN, et al: Loss of heterozygosity at $1 \mathrm{p} 36$ independently predicts for disease progression but not decreased overall survival probability in neuroblastoma patients: A Children's Cancer Group study. J Clin Oncol 18: 1888-1899, 2000.

51. Silva DD, Noronha JA, Silva VD and Carvalhal GF: Increased tissue factor expression is an independent predictor of mortality in clear cell carcinoma of the kidney. Int Braz J Urol 40: 499-506, 2014.

52. Zwicker J1, Furie BC and Furie B: Cancer-associated thrombosis. Crit Rev Oncol Hematol 62: 126-136, 2007.

This work is licensed under a Creative Commons Attribution-NonCommercial-NoDerivatives 4.0 International (CC BY-NC-ND 4.0) License. 